\title{
Pedagogical applications of academic literacies theory: a reflection and case study
}

\section{John Wrigglesworth}

Sheffield Hallam University, UK

\section{Abstract}

The development of the academic literacies approach has provided learning developers with a range of powerful tools to help all students to progress through higher education. Twenty years ago, Lea and Street's (1998) report on student writing initiated a debate which encouraged the transformation of writing pedagogy in UK higher education. The goal of the transformation was, and remains, to develop an education system which is expanding, inclusive and accessible.

This paper focuses on the use of the meaning-making resources that students bring to their learning journey and the ones they encounter throughout their study. It outlines the documentation that enacts the rules that govern university practice at task, module, course and institutional level. The paper draws on academic literacies tools to help to clear away misunderstandings about students' use of language. It then outlines Lea and Street's (1998) classification of institutional approaches to the pedagogical challenges of improving student writing.

The case study describes an optional credit-bearing Introduction to Academic Language module on a UK degree course. By conducting a series of analytical tasks, the undergraduates who elected to take the module developed their use of aspects of academic writing including genre, argument and intertextuality. Students were assessed by analysing their own assessment scripts from other disciplinary modules. The academic writing module was evaluated in ways that could evidence recommendations for change at multiple levels. The methods of evaluation follow practices regarded as standard in many university quality processes but were used to transform provision along inclusive, academic literacies lines. 
Keywords: academic literacies; course design; genre pedagogy; learning objectives; student writing

\section{Introduction}

An academic literacies approach to student writing offers a powerful set of analytic tools to learning developers working in complex higher education institutions (HEls). Many of the tools are grounded in an understanding of language and how students use it to create meaning in their assessments. Thus, the use of language and its meaning-making potential can be seen as linking individual students, disciplinary practices, and the policies and procedures of the university.

Lea and Street (1998) opened up a space for a wide-ranging response to student writing, covering student-, disciplinary- and institutional- practices. To overcome the practical difficulties of weighing the impact of such an influential paper, this reflection and case study broadly restricts itself to citing the contributions of two substantial collections of academic literacies research relating to student pedagogy: Jones et al. (1999) and Lillis et al. (2016). As of 2019, these collections bookend a debate which has benefited from these and many other voices.

The aim of this paper is to offer an interpretation and application of the academic literacies toolbox that may be of use to learning developers. Three applications of the academic literacies approach are foregrounded in the opening part of the paper. First, sociolinguistic tools are used to question the notion of 'student deficit'. Second, philosophical tools are used to challenge the idea of the 'transparency of language'. Third, Lea and Street's (1998) analysis of student writing pedagogy (skills, socialisation and academic literacies) is summarised, showing how the 1998 paper asked pedagogical questions rather than supplying answers. The second part of this paper exemplifies one interpretation the academic literacies approach in a case study of an Academic Language module for undergraduates at a university in the UK. The case is unusual as it shows how a module leader applied the academic literacies toolbox to the iterations of the credit-bearing module, one that is within the quality structures of the university. The paper concludes with some reflections on the evaluation of academic literacies interventions and the continued need for a multi-level institutional response to student writing. 


\section{Concerns about student writing}

Lea and Street's (1998) paper developed from research commissioned by the Economic and Social Research Council which addressed concerns about falling literacy standards and critically reviewed models of writing pedagogies in universities (Lea and Street, 1997). The paper looked at student writing in the round, allowing the authors to distinguish between the meaning-making resources that a student brings to their university experience and the academic practices governing those experiences.

Several of the authorities which govern meaning-making in UK HEls are shown in Table 1. An understanding of the authorities and the associated documentation is important for learning developers as the documentation articulates the rules that lecturers are bound by when assessing courses and marking student scripts. Such an understanding of the system, which is often assumed rather than articulated, helps to enable the transformative power of the academic literacies toolbox. At the heart of the system is the individual student and their assessed scripts, which are shown in the first row. A student's script is assessed against the features that the module leader hopes will be learned, as expressed through learning objectives and marking criteria in the module handbook. The module leader constructs these learning objectives to align with the course learning objectives. This alignment process is governed in turn by the quality assurance policies of the institution, the work of the academic registrar, and the recommendations of the Quality Assurance Agency for Higher Education (QAA). The scope and coverage of a particular course is governed by subject benchmarks. This dialogue of jointly governed meaningmaking is the constructive alignment described by Biggs and Tang (2011). These quality processes are translated into student-facing documents such as the module descriptors and assessment tasks (shown in the top half of Table 1). When all this works in harmony, we have a meaning-making regime which places the student script firmly in a 'productive student learning process', involving learning-oriented assessment tasks, the students' evaluative expertise and engagement with feedback (Carless, 2015, p.27).

Table 1. Levels of authority governing a student's assessment task.

\begin{tabular}{|l|l|l|}
\hline Level of Authority & Documentation & Author \\
\hline Student $\ldots \ldots \ldots \ldots \ldots \ldots \ldots$ & Assessment Scripts & Student \\
\hline
\end{tabular}




\begin{tabular}{|c|c|c|}
\hline Marker & $\begin{array}{l}\text { Presentations } \\
\text { Explanation of Assessment } \\
\text { Feedback on Assessment }\end{array}$ & Marker \\
\hline Lecturer & $\begin{array}{l}\text { Lecture (handouts) } \\
\text { Reading List }\end{array}$ & Lecturer \\
\hline Assessment Tasks & $\begin{array}{l}\text { Task Description } \\
\text { Marking Criteria }\end{array}$ & Module Leader \\
\hline Module & Module Descriptor & Module Leader \\
\hline Course & $\begin{array}{l}\text { Definitive Document } \\
\text { [e.g. BA English] }\end{array}$ & Course Leader \\
\hline Department & $\begin{array}{l}\text { Programme Specification [e.g. } \\
\text { English] }\end{array}$ & $\begin{array}{l}\text { Head of } \\
\text { Department }\end{array}$ \\
\hline University Academic Board & $\begin{array}{l}\text { Undergraduate Regulations (Inc. } \\
\text { assessment regulations) }\end{array}$ & $\begin{array}{l}\text { Academic } \\
\text { Registrar }\end{array}$ \\
\hline University Academic Board & Academic Quality Framework & $\begin{array}{l}\text { Academic } \\
\text { Registrar }\end{array}$ \\
\hline Subject Level & $\begin{array}{l}\text { [English] Subject Benchmark } \\
\text { Statement (2014) }\end{array}$ & $\begin{array}{l}\text { Review groups } \\
\text { from discipline }\end{array}$ \\
\hline $\begin{array}{l}\text { Quality Assurance Agency } \\
\text { for Higher Education (QAA) }\end{array}$ & $\begin{array}{l}\text { The revised UK Quality code for } \\
\text { Higher Education (2018) }\end{array}$ & Chief Executive \\
\hline Department of Education & Government Policy & $\begin{array}{l}\text { Secretary of State } \\
\text { for Education }\end{array}$ \\
\hline
\end{tabular}

The institutional system shown in Table 1 is complex and rigid but transformable. Each level has its own meaning-making language, its documentation and review processes and they are interlinked; however, there can be institutional misunderstandings within and between the levels, rather than a seamless constructive alignment. The key point for a learning developer with a transformative agenda is to identify the level at which a particular change needs to take place. This paper discusses writing pedagogy but emphasises that pedagogical changes need to be aligned with changes elsewhere, for example, in the assessment tasks on a module. Learning developers occasion positive transformation through their pedagogy when they understand, transform and re-align to the system.

Lea and Street $(1997 ; 1998$ p.160) drew on an 'ethnographic style' approach to understand academic literacies within educational systems. They found that a rich description of student writing could productively include the documentation of the various governors in the system, student scripts, and lecturer feedback on those scripts. Such an all embracing linguistic ethnography has developed recently through the various contributions of academic literacies researchers (in particular Lillis, 2008). The ethnographic style allows the individual student's voice to be heard through the collection of rich qualitative data. 
The individual student and their relationship with the governing authorities are at the heart of many, if not all, academic literacies' studies. Students bring their own meanings to university courses, meanings which have developed in a personal biography forged in the various cultures of the widening group of people who participate in higher education. Student voices, their transformations and the variety of disciplinary contexts are part of the move to literacies rather than a single idea of literacy. Academic literacies researchers strive to provide not only the methodological tools for understanding and transforming the education system and the various academic disciplines, but also tools for understanding and transforming the student, while allowing their voice to be respected and included. Three areas that impede a productive and equal dialogue between student and institution are discussed below: first, the deficit model; second, the transparency of language model are challenged; then, third, Lea and Street's critique of dominant student writing pedagogies is outlined.

Non-standard or unexpected use of language does not indicate a deficit in academic ability or potential. This argument was crystalized by New Literacy Studies and is a key academic literacies analytical tool. Drawing on a range of sociolinguistic studies, Gee (2015) demonstrates that language usage follows social enculturation and that prioritizing one usage over another is merely an exercise of social power. Gee argues that we ought to explicate any theory which gives one social group an advantage over another and so gives normative force to his anti-elitist demolition of claims that some cultures are inherently deficit. As Gee (2015, p.23) says, 'theory and meaning are moral matters'. It is probably fair to say that few learning developers would argue that certain students are irreversibly held back by 'deficits' in their social or ethnic background. Individual students may well, however, have something to learn about variations in how other social groups interpret instances of language use. Lea and Street (1998, p.159) put it like this: 'one explanation for problems in student writing might be the gaps between academic staff expectations and student interpretations of what is involved in student writing'.

These gaps in expectations are explored in the research collected in Jones et al. (1999). Hermerschmidt (1999) encapsulates the point when she states, 'there appears to be a need to explore the relationship between the teaching practices that feel natural and familiar to teachers and lecturers and the practices that students have learned and that 
feel natural and familiar to them' (1999, p.5). Jones (1999, p.150) makes the argument through describing how language works:

In construing language as 'transparent', it has effectively denied its workings. So in other words, when language is working well, it is invisible. Conversely, however, when language becomes 'visible', it is an object of censure, marking a deficiency in the individual using it. Additionally, the association of language use in academic discourse with rationality and logic can have the effect of marking out such a student with a deficiency in logic and rationality also.

Scott (1999) agrees that not only do students have the problem of language being seen as transparent, but the individual (the student) is also seen as being deficient. She advocates a 'conception of the writer as a social individual ... an individual as in society, and of society as in the individual' (Scott, 1999, p.172). Highlighting the dangers of individuals bringing their own social understandings to a communicative situation, Lea (1999) evidences a distinction between two approaches that a student may take to an assessment: (1) the reformulation approach, where students make sense of a text by replicating its meaning and authority; and (2) the challenge text, where they bring in their own experience, meanings and understandings to writing the text. Both reformulation and challenge involve the student doing the required reading and assuming they are constructing the required text. However, the challenge text runs the risk of being heard as incoherent and unstructured by the academic marker (who is listening out for the institution's meanings). Lillis (1999), in her case study of ten 'non-traditional' students and their struggle with making sense of the institutional conventions of student writing, accuses HEls directly: 'I argue that confusion is so all pervasive a dimension of their experience as a group of 'non-traditional' students in higher education that it points to an institutional practice of mystery' (Lillis, 1999, p.127). For Lillis, the problem lies with the institution and - once the deficit and the transparency models have been exposed - the academics have a responsibility to listen to all students and make their institutional processes clearer to them. This brings academic literacies practitioners to the issue of whether or not the pedagogy of student writing can be a catalyst for institutional transformation.

Table 2. Models of student writing in higher education (Lea and Street, 1998). \begin{tabular}{l|l} 
Study skills & Student deficit
\end{tabular}

- 'Fix it'; atomised skills; surface language, grammar, spelling. 
- Sources: Behavioural and Experimental Psychology; programmed learning. Student writing as technical and instrumental skill.

\begin{tabular}{|l|l|}
\hline Academic socialisation & Acculturation of students into academic discourse \\
\hline$\bullet$ & Inducting students into new 'culture'; focus on orientation to learning and \\
interpretation of learning tasks, e.g. 'deep', 'surface', 'strategic' learning; \\
homogeneous 'culture', lack of focus on institutional practices, change and \\
power. \\
- Sources: Social Psychology; Anthropology; constructivism \\
\hline Student writing as transparent medium of representation. \\
\hline
\end{tabular}

\begin{tabular}{|l|l|}
\hline Academic literacies & $\begin{array}{l}\text { Student's negotiation of conflicting literacy } \\
\text { practices }\end{array}$ \\
\hline - $\quad$ Literacies as social practices; at level of epistemology and identities; \\
institutions as sites of/constituted in discourse and power; variety of \\
communicative repertoire, e.g. genres, fields, disciplines; switching with \\
regard to linguistic practices, social meanings and identities. \\
- Sources: 'new literacy studies'; critical discourse analysis; systemic functional \\
linguistics; cultural anthropology. \\
\hline Student writing as meaning-making and contested.
\end{tabular}

The three-level classification of student writing pedagogy in higher education (see Table 2) is perhaps the most influential analytic tool to emerge from Lea and Street (1998). Their classification is presented as a hierarchy: the study skills approach is subsumed into academic socialization; academic socialization is subsumed into academic literacies. Only an academic literacies approach fully supports a practices approach that is ideologically informed. At the first level, appropriate instruction about grammar and atomised skills has some value in describing problems in student writing as a technical and instrumental skill; however, the value of this instruction is limited as it does not explain the choices required in using grammar or those for employing the skills needed to thrive in the new academic culture. At the second level, acculturation into a culture that is unfamiliar to a student is of value when making these grammar and skills choices; however, the value of acculturation instruction is limited if the student brings to that instruction a set of meanings which mislead or cloud the understanding of the required academic practice. The academic socialization approach, in Lea and Street's (1998) classification, is defined by an understanding of meaning as transparent; transparent meaning suggests that every student should understand the meaning of a text, or even a particular term, in the same unclouded way.

Applied linguists have had no difficulty debunking this view of meaning. Academic literacies specialists have offered many examples showing that meaning is specific to the Journal of Learning Development in Higher Education, Issue 15: November 2019 
context of particular academic disciplines including terms like 'argument', 'structure', and 'clear'. The difference between the meanings that a student brings to a term (how students use language at home, for example) and the meaning that a History lecturer brings to the same term (as used in a piece of essay feedback) may be as different again from how an engineer uses it (in a case study). The differences are invisible within each group of users but may cause (damaging) breakdowns in communication between them when communicating writing and assessment expectations. To identify these differences and breakdowns in meaning, Lea and Street (1998) adopt the term 'contested', a term which itself means different things to different people.

An academic literacies approach to pedagogy would expand on the study skills and socialization approaches to teach student writing as being both about meaning-making and contested. It would also challenge meaning-making at all levels of Table 1.

\section{Pedagogical implications}

The academic literacies approach takes meaning-making to be contingent on social practice. Looking for pedagogical implications, Lillis (2006) asks: 'what are the design implications for pedagogy?'. She calls attention to task design and two forms of dialogue. Dialogue has a descriptive form where dialogue is unquestioned and clear to all (a given); it also has an ideal form which is something cloudy and requires some struggle to understand. The struggle is made possible by a social tension between cultural claims of monologism (one truth, voice, identity, authority) and dialogism (many truths, voices, identities, discourses). Once learning developers have task design and dialogue in their conceptual toolbox, they open up a pedagogical space for helping students with their own writing: feedback opens into talkback; disciplinary content opens to other interests; and academic writing conventions become open to other ways of meaning-making (Lillis, 2003, pp.204 - 205).

Task pedagogy and dialogue are key in two papers from the Student Writing in the University collection (Jones et al., 1999). English is concerned about her EAP students' successes in their essay writing and recognises that 'without having a clear picture of the exact nature of the problem it is impossible to provide the information that the student really needs to understand what is going wrong' (English, 1999, p.19). The clear picture is 
framed using an understanding of functional linguistics to conduct a close textual analysis of topic and comment, cohesive relationships, and propositions in her students' scripts (see Halliday and Matthiessen, 2014). In using this description of language, English is indicating the potential of systemic functional linguistics to inform an academic literacies approach, a potential indicated in Lea and Street (1998; see Table 2). The picture is developed within a tutorial, which facilitates deep insights such that a learning developer can see the problem and 'the student can begin to see how to move forward' (English, 1999, p31). However, the detailed dialogue of an individual tutorial is an affordance that is not always resourced in mass education systems.

Enhancing students' ability to move forward with their academic writing is also the purpose of Jones' (1999) task-based programme. She is interested in pre-empting problems by adequately preparing groups of students for their studies within the (explicit version of the) academic socialization model, but she draws on Lea and Street's (1998) academic literacies insights about disciplinary epistemology and individual student identities. Jones (1999, p.56) provides an 'interim context' using academic socialization drawing on academic literacies insights and task-based pedagogical design to empower groups of students to interact positively with their disciplines, institutions and the wider world.

A recent collection of case studies (Lillis et al., 2016) reports on recent applications of the academic literacies toolbox. Equipping students to gain control of both texts and practices remains a key purpose of provision, often through explicit pedagogical tasks (Gimenez and Thomas, 2016, p.30). In terms of practice, Gimenez and Thomas (2016) offer techniques of collective meaning-making and for challenging the power of the author, which help students gain access to difficult readings. To help students with text analysis, they offer processes of deconstruction and construction/composition akin to those found in systemic functional linguistics (SFL) approaches to genre pedagogy (Martin, 1997; Martin and Rose, 2003, Martin and Rose, 2008), but the processes place emphasis on drafting and the range of possible interpretations of, and creativity in, the text. Similarly, Fischer's (2016) research addresses questions surrounding explicit instruction. She found that teachers were aware that 'hidden' expectations were not being articulated to students successfully; moreover, students were wrongly convinced they had understood, but did not have the resources to critique and adapt how they were making sense of the text. Neither teachers nor students had control of the (non-transparent) genres and pedagogy. Fisher's writing 
course provided the opportunity to uncover and address deeper literacy practices buried in the textual practices underpinning the assessment.

Challenging the transparent generic skills approach in favour of one recognising academic writing as a contestable social practice formed by dominant ideologies, Badenhorst et al. (2016, p.99) state their transformative agenda concisely:

to open student's eyes to their position and roles within their respective disciplinary discourse, and provide them with a range of techniques and perspectives to allow them to engage the tension of living inside the system but thinking outside it.

Their course was built of tasks where discipline-specific texts were deconstructed in groups, and feedback about the product of composition tasks was discussed. Emphasis was placed on developing an understanding of epistemologies and choice rather than normative 'best practice'. Discussion, joint meaning-making and contingency set the tone of the discussions of the disciplinary genres. Through discussion of how the system functions, transformative learning became possible, as 'rules were not abolished but revealed' (Badenhorst et al. 2016, p. 105). The choices made by students became 'informed choices' (Badenhorst et al., 2016). Similarly, Chanock et al. (2016) highlight voice and choice but importantly list specific sentence level features (technical vocabulary, abstract nominalizations, third person, passive voice, verbal process types and concrete grammatical subjects) that depend on the choices. Through their pedagogy, students see how these informed choices differed across registers and when they moved from written assessments to presentations.

English (2016) also problematizes approaches to genre pedagogy in higher education. Genre pedagogy can have disempowering results: students producing genres rather than producing knowledge; a display of a template rather than a meaning-making process; or a settling on form rather than an engagement with content. English (2016, p.246) proposes 'regenring' in which a student takes a previously submitted assessment text and re-writes it in a different genre (e.g. a scripted radio debate between two economists). English then offers a useful 'social orientations of genre' framework for analysing the choices made during the regenring process. This process gives the student a delicate set of informed language choices, not dissimilar to the SFL-orientated model suggested by, for example, Paltridge (1997), but highlighting transformation in meaning-making. 


\section{Case study: an Introduction to Academic Language module}

The module, Introduction to Academic Language, is used here to exemplify a process of including an academic literacies approach to student writing into an undergraduate course at a post-92 university in the UK. The module was a first year, semester two, 20-credit option on a suite of BA courses: English Language and Literature; Journalism and English Language; English Studies; and Communication and English Studies. It lasted 15 weeks and had three hours a week of contact time. The number of students taking the option grew from 18 in the first iteration to 38 in the fifth. The case study draws on the development of the module over five iterations of the course.

Throughout the delivery of the module, evaluation was conducted using three sets of data. Ellis (2011) distinguishes between macro-evaluation (concerned with the effectiveness and efficiency of meeting the programme goals) and micro-evaluation (concerned with smaller, contributory units of analysis like task performance or an aspect of learner participation). First, the students completed a generic, final-week module feedback questionnaire (macro); the questionnaire data was used by module leaders to inform the development of the learning objectives, syllabus, assessment and pedagogy. The questionnaire data fed back into both the module- and course- evaluation; this informed the alignment of the module with the students' future concerns. Second, the lecturer kept a (micro-evaluation) reflective diary on the materials each week; these notes were used to develop the effectiveness of each pedagogical task. Third, the students' assessment scripts provide data on whether target learning objectives were being met; can they write, cite and think in the expected ways (macro)? All the data was collected as normal university practice within the ethical and quality procedures of the university. Students gave their permission for the data to be used for research purposes in addition to course evaluation. A significant gap in the evaluation is tracking data (i.e. evaluation data for the module has not been matched to data on over all course performance, degree classification or demographic data).

The challenge for teaching the module was to demonstrate the value of a series of tasks that develop study skills and academic socialization understood through an academic literacies lens (Lea and Street, 1998). As a first-year module, it has a role in pre-empting problems similar to Jones' interim context (1999). As the module took shape during the 
first and second iterations, it became clear that the demonstration of value was needed in four spheres of governorship. The spheres are: the practices of teaching the module; the practices of assessing the module; the practices of the discipline; and the university's accreditation practices. The academic literacies approach has the aspiration to enhance all four.

The practice of teaching a module is shaped by the learning objectives and the pedagogy. Table 3 shows objectives for the Academic Language module based on the initial brief from the course leader. They reflect a skills approach with LO4 allowing for academic socialization input. The action verbs are a stage towards operationalizing 'gain control' through explicit teaching (Gimenez and Thomas, 2016), where gain control is understood as critically selecting from the meaning-making resource of language and developing an evaluative expertise towards learning (Carless, 2015). The pedagogy of the tasks attempted to deliver these objectives with an additional academic literacies sense.

Table 3. Learning objectives on the Introduction to Academic Language module.

On successful completion of the unit students will be able, at threshold level, to:

LO 1 Differentiate and critically appraise a variety of written academic genres and text-types.

LO 2 Plan, execute, and evaluate the process of constructing an academic text.

LO 3 Construct and develop an appropriately structured text in named academic macro-genres (e.g. essay, report, dissertation) and micro-genres (e.g. explanation, recount, argument).

LO 4 Understand and apply the expectations of academic genres within their own discipline.

LO 5 Identify and label a variety of grammatical functions (Theme and New, HyperTheme, directives, discourse markers, citation verbs, noun phrases).

The module tasks are sequenced over a 15-week syllabus (Table 4). Many tasks were based on genre pedagogy (Martin, 1997; 1999). In genre pedagogy, students establish the purpose and stages of socially situated texts in a deconstruction/reconstruction cycle. A pedagogical task in session one looked at the micro-genre of explanation as applied to the learning objectives in the module handbook (a 300-word text). Once the students saw the purpose and stages, the stages were analysed for grammatical choices (question forms, declarative statements and imperatives, see Badenhorst et al., 2016). Students were asked to evaluate the content of the learning objectives and identify other things they 
could learn on the module, and critique the grammatical options that could be selected to construe the objectives. Although there is an element of mental gymnastics in the transformation, understanding the governed contingency of the objectives and how they are expressed grammatically are notions that are transferable to future contexts. The tasks developed evaluative expertise and are a stage towards gaining control. Formal modifications of the module specification eventually introduced these verbs into the learning objectives.

Focussing on a later stage in a student's assessment journey, the fourth iteration of the module included a more complex genre than explanation. The students conducted a genre analysis of lecturer feedback on assessed student scripts and evaluated its relationship to marking criteria. In highlighting the practices behind both genres (script and feedback) and the value of both, the tasks opened up the space to evaluate and possibly challenge feedback. The analysis was scheduled in week eight, when the students had received feedback on their own assessment task one scripts. This space for dialogue allows for these negotiations of meaning, particularly on their own texts, and helped draw attention to academic literacies ideas about feedback and feedforward. It was also a learning opportunity for the lecturer who had written the feedback.

Table 4. Syllabus for the Introduction to Academic Language module.

\begin{tabular}{|c|c|c|}
\hline Session & \multicolumn{2}{|l|}{ Title } \\
\hline 1 & \multicolumn{2}{|l|}{ Introduction to writing at university } \\
\hline 2 & \multicolumn{2}{|c|}{ Who and why of academic writing: discourse communities and genre } \\
\hline 3 & \multicolumn{2}{|l|}{ How to build a text: genre and structure } \\
\hline 4 & \multicolumn{2}{|l|}{ Academic argument 1} \\
\hline 5 & \multicolumn{2}{|l|}{ Fitting a text together: cohesion } \\
\hline 6 & $\begin{array}{l}\text { Acknowledging the role of other people's work: } \\
\text { citation }\end{array}$ & $\begin{array}{l}\text { Submission of } \\
\text { First } \\
\text { Assessment } \\
\text { Task }\end{array}$ \\
\hline 7 & \multicolumn{2}{|l|}{ Paragraph structure, summarizing and referencing } \\
\hline 8 & \multicolumn{2}{|l|}{ Review } \\
\hline 9 & \multicolumn{2}{|l|}{ Macro- and micro-genres; intertextuality } \\
\hline 10 & \multicolumn{2}{|l|}{ Genre and academic argument 2} \\
\hline 11 & \multicolumn{2}{|l|}{ Signposting, meta-discourse and noun phrases } \\
\hline 12 & \multicolumn{2}{|l|}{ Genre and academic argument 3} \\
\hline 13 & \multicolumn{2}{|l|}{ Student writing as social practice } \\
\hline 14 & Review & $\begin{array}{l}\text { Submission of } \\
\text { Second } \\
\text { Assessment } \\
\text { Task }\end{array}$ \\
\hline
\end{tabular}


In addition to teaching a genre approach to texts, there are three sessions using argument theory. Students started with Riddle's (2000) model, which identifies three logical operators (then, because, since). They then used Toulmin's (1958/2003) approach, first to popular genres and then academic ones. Toulmin lays out the structure of an argument using five terms: conclusion, warrant, backing, data, and qualifier. Distinguishing formal argument structure from genre stages proved to be a successful way of gaining control of a text. The students were given YouTube links for an episode of the American courtroom reality-TV show, Judge Judy. An infamous episode - Kelli Filkin's 'eBay scammer' case was analysed both as a genre (the show's format transcribed as a printed script) and using Toulmin's approach (the legal argument behind the case). Students regenred the Judge Judy script in this activity, moving from script to academic summary via a Toulmin (1958/2003) analysis. The grammatical transformation is from commonplace to academic language (counter to English's, 2016, direction). Consciousness raising activities were used with examples of target academic texts to introduce the use of complex noun phrases, including ones for taxonomy and abstraction, and to demonstrate how sections of text can be controlled and re-packaged in noun phrases. Each phase in the pedagogical loop is evaluated as a separate task with the overall purpose being evaluated in the module questionnaire in an item about student confidence in gaining control of genre and argument (early iterations referred to use rather than control).

The third session on argument combines genre analysis, argument analysis and intertextuality. Students were given the prompt question: 'What is the use and origin of the term "OK"?' and four authentic sources. The sources enact different genres but all present evidence for a (different) entomological conclusion. The students worked through this complex task in three pedagogical loops: in-class genre- and Toulmin- analysis of one source; at-home pair analysis of genre and Toulmin analysis (1958/2003) of two sources; and individual analysis of the fourth. The meaning-making resource was citation verbs and how they enact an evaluative function (based on Thompson and Ye, 1991) when presenting other voices in a text.

The academic literacies lens gains additional focus through the design of the module assessment tasks. The two assessment tasks report on an analysis of, and reflection on, work in the students' other modules (Table 5). The analysis is conducted using the meaning-making tools taught on the module and the reflection is based on an evolving Journal of Learning Development in Higher Education, Issue 15: November 2019 
understanding of academic literacies. The tasks remained the same over the five iterations but the wording of the rubrics was revised in the light of feedback. In module feedback, the students requested the details of the length of the introduction and conclusion and an annotated example script, both 'study skills' prescriptions. Irrespective of the improvements to the clarity of the rubric, students always had questions. These can be classified into three groups: meaning-checking questions, as for the expression 'a piece of writing that you are yet to submit' in Task 2; definitional questions, especially around what counted as one linguistic tool and a set; and haven't-read-the-handbook questions. Lillis's advice about 'clarity' and talkback were invaluable in helping to ensure that opportunities were made for every student to make sense and gain control of assessment processes. The opportunity for different understandings and the possibility of addressing them is a feature of academic literacies and it was modelled, explicitly highlighted and encouraged in the sessions. This level of detail is difficult to capture on the generic feedback forms so maintaining dialogue with individual students in class time remained the preferred mode of approaching clarity.

However, the richest resource for change were the scripts that students submitted for assessment and the deviations from disciplinary expectations in them. At issue was an understanding of the reading-into-application into application-into-writing nature of the assessment task. Students need to understand genre and argument analysis, how to critique their own assessment scripts as data, and then how to write a new assessment script for the assessment task. The successful assessment scripts (a reformulation in Lea's, 1999, terms) may indicate that the student had followed the practices modelled in the sessions. However, identifying a challenge or a confused text required discussion with the student. Subject specialists develop their skills for spotting confusions in disciplinespecific practices; the academic literacies approach helps to add an understanding of meaning-making to those skills and tools to understand the nature of the challenge/confusion.

Table 5. Assessment tasks on the Introduction to Academic Language module.

\section{Assessment Task 1: Report on Academic Genre Submission (500 words; $40 \%$} of final mark)

You should conduct a genre analysis of one of your assessed scripts from Semester 1 using the tools practiced in Sessions $1-6$. You must define genre, genre analysis and one other tool. Then outline a genre analysis of the script linking the tool to the functional stages of the genre. Include an explanation of how your 
script exemplifies its mis/use. You should append a copy of the assessed script from Semester 1.

Assessment Task 2: Report on Academic Genre Draft (1000 words; $60 \%$ of final mark)

You should describe the process before, and analyse the product of, a piece of writing that you are yet to submit (i.e. a draft) in Semester 2. You should choose two tools from Sessions $1-14$ to use in the analysis. You must give a cited definition and exemplification of how the two tools work to achieve the purpose of the text. You should append a copy of your draft from Semester 2.

If the syllabus is to evidence pedagogical value beyond the module through its use of an academic literacies approach, a wider application to other courses would be required. The intention is that the learning objectives of the writing module are not bound to one discipline. The assessment tasks concern the tools and practices involved in working with academic discourse and 'piggy-back' on the practices and texts that the students are working with in their own field.

There is an opportunity for a transformative effect on course descriptions. The institutional point where disciplinary practices meet assessment in the course documentation is in the module description of assessment tasks. Coursework is classified as one of several macro-genres: essay; report; project; dissertation etc. As descriptions of assessment meaning-making resources, these macro-genres have a role in assessment documentation but are blunt instruments in explaining disciplinary practices. Wrigglesworth and McKeever (2010) show how component micro-genres can be described in one discipline, History, using genre analysis and ethnographic interviews. Their research produced a description of a document commentary, a micro-genre which can be freestanding or part of a longer piece of historical argumentation. Detailed descriptions of assessment requirements, presented in the terminology of the Introduction to Academic Language module and linked to meaning-making resources (such as in Table 4) would better explain disciplinary practices and together help address the accusation of 'an institutional practice of mystery' (Lillis, 1999, p.127). The module learning objectives would need to align with all course descriptions, using a common description of meaning-making resources (e.g. those here draw on SFL). If students are equipped with the analytical tools they can feed back to lecturers more effectively and explain their challenges to existing provision. Implementing such a move requires demonstrating the value of this type of pedagogy at the level of the university's accreditation practices, which arguably requires Journal of Learning Development in Higher Education, Issue 15: November 2019 
extensive tracking projects of a scope which is beyond the case-study and ethnographic approaches to academic literacies.

\section{Conclusion}

An academic literacies approach calls for learning developers to engage with the whole education system. It recognises that language use is socially situated, varies with context, and is neither transparent to its users nor indicative of cultural deficits. It helps clear away misunderstandings about the student journey and the ways that students learn and write about disciplinary practices. It understands that a student's struggle to make sense of academic and disciplinary tasks may be rooted in miscommunications from one or more of the institutional levels identified in Table 1.

Lea and Street's (1998) paper classified ways to teach student writing. It gave a challenge to educationalists across the academy: how might we teach students to use academic language? This paper has added a case study of a credit-bearing module in the first year of an undergraduate course to the literature that answers that question. The learning objectives of the module included using explanations of academic genre, argument, intertextuality and lexico-grammatical features of academic style. It brought disciplinary writing practices to students' attention by asking them to analyse the writing they are doing in other modules. The explanatory force of those explanations helps to equip students with the tools to work with, gain control of, and critically evaluate the meaning-making resources behind disciplinary assessment practices. The module is an interim context (Jones, 1999, p.56) and as such requires the support of module leaders in the following semesters of study. That support manifests itself in how assessment tasks are explained (e.g. discipline-specific micro genres) and how feedback is formulated (e.g. noting how cohesive features improve clarity). Whether a module about controlling meaning-making resources could replace study skills modules across all faculties or would have restricted application in a single faculty or department is a question for further pedagogical research.

The experience of developing a for-credit Academic Language module put the learning developer in two roles: a module leader with learning objectives to teach and an assessment board to report to; and an academic literacies practitioner with an oppositional, transformative lens. Learning developers may have their greatest impact on 
refining academic writing pedagogy but also need to understand and engage with all the levels of academic governorship. They recognise that students' prior meaning-making experiences need to be built into a pedagogical approach and that the tasks are evaluated through an academic literacies' lens. Nevertheless, the provision has also to deliver in terms that the other governors of the system recognise as valuable: disciplinary writing practices and assessment board practices enable as well as constrain student success. Thus, the account given here suggests the adoption of a more accommodating stance than some of the more oppositional stances in the literature. It has suggested negotiation of meaning at different levels of the institution which might be seen as slow to bear fruit. The stance, however, is built on progressive ambitions and the academic literacies case study research that continues to open up the space for progress. Indeed, an optional forcredit module on academic writing would not have found its way onto the course structure if it were not for the pioneering work in Lea and Street (1998).

\section{References}

Badenhorst, C., Moloney, C., Dyer, J., Rosales, J., and Murray, M. (2016) 'Thinking creatively about research writing', in Lillis, T., Harrington, K., Lea, M., and Mitchell, S. (eds.), Working with academic literacies; case studies towards transformative practice. Fort Collins, CO: The WAC Clearinghouse, pp. 97-106.

Biggs, J. and Tang, C. (2011) Teaching for quality learning at university: what the student does. 4th edn. Maidenhead: Open University Press, McGraw-Hill Education.

Carless, D. (2015) Excellence in University Assessment: Learning from award-winning practice. London: Routledge.

Chanock, K., Whitmore, S. and Nishitani, M. (2016) Exploring constraints and choices in a thesis writing circle, in Lillis, T., Harrington, K., Lea, M., and Mitchell, S. (eds.), Working with academic literacies; case studies towards transformative practice. Fort Collins, CO: The WAC Clearinghouse, pp. 107-116. 
Ellis, R. (2011) 'Macro- and micro-evaluations of task-based teaching', in Tomlinson, B. (ed.) Materials Development in Language Teaching (2nd ed). Cambridge: Cambridge University Press, pp. 212-35.

English, F. (1999) 'What do students really say in their essays? Towards a descriptive framework for analysing student writing', in Jones, C., Turner, J. and Street, B. (eds.) Students writing in the university. Amsterdam: John Benjamins Publishing Company, pp. 17-36.

English, F. (2016) 'Genre as a pedagogical resource at university', in Lillis, T., Harrington, K., Lea, M., and Mitchell, S. (eds.), Working with academic literacies; case studies towards transformative practice. Fort Collins, CO: The WAC Clearinghouse, pp. 245-256.

Fischer, A. (2016) "'Hidden features" and "overt instruction" in academic literacies practices: a case study in engineering', in Lillis, T., Harrington, K., Lea, M., and Mitchell, S. (eds.), Working with academic literacies; case studies towards transformative practice. Fort Collins, CO: The WAC Clearinghouse, pp. 75-86.

Gimenez, J. and Thomas, P. (2016) 'A framework for usable pedagogy: case studies towards accessibility, criticality and visibility', in Lillis, T., Harrington, K., Lea, M., and Mitchell, S. (eds.), Working with academic literacies; case studies towards transformative practice. Fort Collins, CO: The WAC Clearinghouse, pp. 29-44.

Gee, J. P. (2015) Social linguistics and literacies: ideology in discourses. $5^{\text {th }}$ edn. London: Routledge.

Halliday, M.A.K. and Matthiessen C. (2014) Halliday's Introduction to Functional Grammar $4^{\text {th }}$ edn. London: Routledge.

Hermerschmidt, M. (1999) 'Foregrounding background in academic learning', in Jones, C., Turner, J. and Street, B. (eds.) Students writing in the university. Amsterdam: John Benjamins Publishing Company, pp. 5-16. 
Jones, C. (1999) 'The student from overseas and the British university: finding a way to succeed', in Jones, C., Turner, J. and Street, B. (eds.) Students writing in the university. Amsterdam: John Benjamins Publishing Company, pp. 37-60.

Jones, C., Turner, J. and Street, B. (1999) Students writing in the university. Amsterdam: John Benjamins Publishing Company.

Lea, M. (1999) 'Academic literacies and learning in higher education: construction knowledge through texts and experience', in Jones, C., Turner, J. and Street, B. (eds.) Students writing in the university. Amsterdam: John Benjamins Publishing Company, pp. 103-124.

Lea, M. and Street, B. V. (1997) Student writing and staff feedback in higher education: an academic literacies approach. Swindon: Economic and Social Research Council.

Lea, M. and Street, B. (1998) Student writing in higher education: an academic literacies approach, Studies in Higher Education, 23(2), pp. 157-72.

Lillis, T. (1999) 'Whose 'common sense'? Essayist literacy and the institutional practice of mystery', in Jones, C., Turner, J. and Street, B. (eds.) Students writing in the university. Amsterdam: John Benjamins Publishing Company, pp. 127-148.

Lillis, T. (2003) Student writing as 'academic literacies': drawing on Bakhtin to move from critique to design. Language and Education, 17(3), 192-207.

Lillis, T. (2006). Moving towards an academic literacies pedagogy: 'dialogues of participation.' In Ganobscik-Williams, L. (Ed.), Teaching academic writing in UK higher education: theories, practices and models. Basingstoke: Palgrave, pp. 30-45.

Lillis, T. M. (2008) Ethnography as method, methodology, and "deep theorizing": closing the gap between text and context in academic writing research. Written Communication, 25(3), pp. 353-388. 
Lillis, T., Harrington, K., Lea, M., and Mitchell, S. (eds.) (2016) Working with Academic Literacies; case studies towards transformative practice. Fort Collins, CO: The WAC Clearinghouse.

Martin, J.R. (1997) 'Analysing genre: functional parameters', in Martin, J.R. and Christie, F. (eds.) Genre and Institutions; social processes in the workplace and school. London: Continuum.

Martin, J.R. (1999) Mentoring semogenesis: 'genre-based' literacy practices, in Christie, F. (ed.) Pedagogy and the shaping of consciousness; linguistic and social processes. London: Continuum.

Martin, J.R. and Rose, D. (2003) Working with discourse; meaning beyond the clause. London: Continuum.

Martin, J.R. and Rose, D. (2008) Genre relations: mapping culture. London: Equinox.

Paltridge, B. (1997) Genre and the language learning classroom. Ann Arbor, MI: University of Michigan Press.

Riddle, M. (2000) 'Improving argument by parts', in Mitchell, S. and Andrews, R. (eds.) Learning to argue in higher education. Portsmouth, NH: Heinemann, Boynton/Cook, pp. 53-64.

Scott, M. (1999) 'Agency and subjectivity in student writing', in Jones, C., Turner, J. and Street, B. (eds.) Students writing in the university. Amsterdam: John Benjamins Publishing Company, pp. 171-192.

Thompson, G and Ye, Y. (1991) 'Evaluation in the reporting verbs used in academic papers', Applied Linguistics, 12(4), pp. 365-382.

Toulmin, S. (1958/2003) The uses of argument (updated edition). Cambridge: Cambridge University Press. 
Wrigglesworth, J. and McKeever, M. (2010) 'Writing history: a genre-based, interdisciplinary approach linking disciplines, language and academic skills', Arts and Humanities in Higher Education, 9(1), pp. 107-126.

\section{Author details}

John Wrigglesworth has researched and taught EFL and EAP using systemic functional linguistics, models of genre, and academic literacies in UK higher education for seventeen years. He takes a learner centred approach in both his English language and teacher education courses. 